\title{
Adverse Event Duration
}

National Cancer Institute

\section{Source}

National Cancer Institute. Adverse Event Duration. NCI Thesaurus. Code C83200.

The period of time from start to finish of an adverse event. 